\section{Prevalence of Incidental Dental Anomalies seen on Pre-Treatment Digital Panoramic Radiographs of a Group of Nigerian Orthodontic Patients: A Retrospective Study}

Elfleda Angelina AIKINS, Chinyere UTUTU, Emmanuel Ifeanyi CHUKWUMA

[Department of Child Dental Health, Faculty of Dentistry, College of Health Sciences, University of Port Harcourt, Port Harcourt, Rivers State, Nigeria]

\section{Correspondence}

Dr. Chinyere Ututu

Department of Child Dental Health, University of Port Harcourt Teaching Hospital, Choba, Port Harcourt, Rivers State, Nigeria

Email: chinyereututu@yahoo.com

Elfleda A. Aikins

https://orcid.org/ 0000-0002-8218-4477

Chinyere Ututu

https://orcid.org/0000-0002-4176-0976

Emmanuel I. Chukwuma

https://orcid.org/0000-0002-4555-9196

Citation: Aikins EA, Ututu C, Chukwuma El. Prevalence of Incidental Dental Anomalies seen on Pre-Treatment Digital Panoramic Radiographs of a Group of Nigerian Orthodontic Patients: A Retrospective Study. Nig J Dent Res 2022; 7(1): 67-74

\section{ABSTRACT}

Background: Radiographs are used by orthodontists in the diagnosis of malocclusion, treatment planning and monitoring. These usually reveal presence of dental anomalies that may require further assessment and management.

Objective: To investigate the prevalence, types and distribution of dental anomalies seen on the orthopantomograms (OPGs) of orthodontic patients at the University of Port-Harcourt Teaching Hospital (UPTH).

Methods: This was a retrospective cross-sectional radiographic study of a cohort of orthodontic patients who presented to the Department of Child Dental Health, University of Port Harcourt Teaching Hospital, Rivers State, Nigeria. The data gathered from digital orthopantomograms of the patients was analysed using IBM Statistical Package for Social Sciences (SPSS) Statistics for Windows version 25.0.

Results: The study comprised 249 patients with an age range of 5-44years (mean age of $14.6 \pm 7$-7years) comprising $108(43.4 \%)$ males and $141(56.6 \%)$ females. Seventy (28.1\%) [(29, 41.4\% males), $(41,58.6 \%$ females $)]$ of the patients had at least one dental anomaly. Dental anomalies were commonest $(48,68.6 \%)$ within $10-19$ years age bracket followed by the $0-9$ years age bracket (11, 15.7\%). The most frequent dental anomaly was taurodontism (43, $61.4 \%)$, followed by congenitally missing teeth $(8,11.4 \%)$, supernumerary teeth $(5,7.1 \%)$, odontoma $(4,5.7 \%)$, peg shaped lateral incisors and transposition (2, 2.9\%) respectively. Dental anomalies were more frequent in the maxilla $(43,61.4 \%)$.

Conclusion: The most common dental anomaly was taurodontism. Anomalies were more frequent in female than male patients and in the maxilla than in the mandible. Keywords: Dental anomalies, digital orthopantomogram, orthodontic patients, University of Port Harcourt Teaching Hospital, Nigeria

Received: 4 Dec, 2021

Revision: 15 Dec, 2021

Accepted: 16 Dec, 2021 


\section{INTRODUCTION}

The orthopantomogram (OPG) which shows the jaws, teeth and surrounding structures is an efficient tool in treatment planning as well as monitoring and evaluation of treatment outcome of orthodontic patients. ${ }^{1}$ It is very useful in assessing tooth morphology, eruption sequence and stage, missing and spatial relationships of teeth and thus assessing dental anomalies. ${ }^{2}$

Dental anomalies are relatively common dental pathologies present in both primary and permanent dentitions with a prevalence rate of $18.17-56.9 \%$ depending on regional and racial variation of the study population..$^{3-9}$ The prevalence of dental anomalies among the Saudi Arabians is $36.3^{3} \%^{3}$ while it is $56.9 \%$ among Brazillians ${ }^{4}, 18.17 \%$ among Iranians ${ }^{7}, 23.7 \%$ among the Sudanese ${ }^{8}$ and $26.6 \%$ among South Western Nigerians. ${ }^{9}$ The prevalence of congenitally missing teeth among Saudi Arabians is $24.77 \%$. Peg-shaped lateral incisors had a prevalence of $0.9 \%$ among South Western Nigerians. They may exist in isolation or sometimes as a part of a syndrome especially when multiple. ${ }^{4,6}$ Aetiology is largely unknown, although genetics and environmental factors are said to be contributory. $4,6,10,11$ These anomalies may be incidental findings on $x$-rays (incidental dental anomalies) taken during routine orthodontic screenings for example taurodontism, odontoma, bifid roots and supernumerary. ${ }^{2}$ Dental anomalies for example supernumerary teeth and transposition, constitute aesthetic and functional challenges and are causal factors of malocclusion, dental caries and periodontal diseases. ${ }^{2-4,9}$

Various dental anomalies can limit treatment options, ${ }^{2-4,12}$ thus, early diagnosis is important in treatment planning and reduction of possible future dental complications. ${ }^{3,4,9}$ Evaluation of patients with dental anomalies requires a detailed family, medical, dental and clinical history and examination and radiographic evaluation as well as certain laboratory tests. ${ }^{6}$

The study aimed to investigate the prevalence, types and distribution of dental anomalies seen on the pretreatment OPG's of orthodontic patients at the University of Port-Harcourt Teaching Hospital (UPTH)

\section{MATERIALS AND METHODS}

Ethical approval was applied for and obtained from the Research and Ethics Committee of the hospital prior to commencement of this retrospective study (UPTH/ADM/9o/S.II/VOL.XI/446). The study comprised a cohort of two hundred and forty-nine patients aged 5-44years who presented for treatment at the Orthodontic Clinic in the Department of Child Dental Health, University of Port Harcourt Teaching Hospital, Port Harcourt, Nigeria and had orthopantomograms taken between September 2015 to August 2021.

Sociodemographic data of each patient which was elicited from their folders, presence or absence, types and location of dental anomalies as seen on each orthopantomogram were recorded on a standard proforma. All patients between the age of 5-44years with OPG and complete records were included in the study. Patients with incomplete sociodemographic records, congenital cranio-facial anomalies or syndrome, previous head and neck surgery and previous orthodontic treatment were excluded from the study.

Each radiograph was assessed independently by two authors after which findings were compared. Where the findings were dissimilar, the third author assessed the radiograph. To assess intra-examiner agreement, after four weeks, $10 \%$ of the total sample was randomly selected and re-assessed. Kappa values of 0.95 and 0.89 suggested acceptable levels of intra-observer and inter-observer reliabilities, respectively. Data analysis was carried out using IBM Statistical Package for Social Sciences (SPSS) Statistics for Windows version 25.0.(Armonk, NY:IBMCorp).

The results were presented using frequencies, percentages and proportions for categorical variables and means and standard deviations for continuous variables. Chi-square was used to test association among dental anomalies, age and gender. Statistical significance was determined at $95 \%$ confidence interval and at $p<0.05$.

\section{RESULTS}

The study comprised a total of 249 patients with an age range of 5-44years (mean age of $14.6 \pm 7.7$ years). There were $108(43.4 \%)$ males and 141 (56.6\%) females. Table1 shows the age and gender distribution of the study participants. 
Seventy patients (28.1\%) [(29, 41.4\% males), (41, $58.6 \%$ females) had at least one dental anomaly. Four $(5.7 \%)$ of the patients had multiple anomalies. Dental anomalies were seen more frequently in the maxilla $(43,61.4 \%)$, followed by combination of both arches $(21,30 \%)$ and least common in the mandible $(6,8.6 \%)$. However, this is statistically not significant $\mathrm{p}=0.24, \mathrm{X}^{2}=28.49$.

Fig 1 shows prevalence of dental arches with dental anomalies.

Fig 2 displays taurodontism of the mandibular first permanent teeth.

Fig 3 shows mandibular mesiodens and congenitally missing maxillary lateral incisors.

Fig 4 displays odontoma.

The most frequent dental anomaly seen existing alone was taurodontism $(43,61.4 \%)$, followed by congenitally missing teeth $(8,11.4 \%)$. Bifid root and dilaceration $(1,1.4 \%$ each) were the least seen. The most common supernumerary seen was the mesiodens $(5,71.4 \%)$, while the paramolar and supplemental $(1,14.3 \%)$ were the least.

Table 2 displays the prevalence of the dental anomalies.

Dental anomalies were seen more frequently in the maxilla as displayed in Table 3 .

Table 4 displays the cross-tabulation of patients' sociodemographic and dental anomalies. Dental anomalies were most common among patients aged $10-19$ years $(48,68.6 \%)$. There was no statistical significance between dental anomalies and gender $\left(p=0.17, X^{2}=16.45\right)$ and between dental anomalies and age $\left(p=0.37, X^{2}=38.31\right)$. Forty-four $(17.7 \%)$ of the patients had taurodontism, out of which one $(2.3 \%)$ had taurodontism co-existing with mesiodens. There was equal distribution $(22,50.0 \%$ each $)$ of taurodontism across affected age brackets between both genders.

Table 5 shows the age, gender and congenitally missing teeth. Eleven patients (4.4\%) had congenitally missing teeth out of which $(9,81.8 \%)$ were females. Out of a total of sixteen congenitally missing teeth, the lateral incisors $(8,50.0 \%)$ were most commonly missing followed by the second premolars $(4,25.0 \%)$.
Table 1: Sociodemographic characteristics of patients

\begin{tabular}{llll}
\hline $\begin{array}{l}\text { Age } \\
\text { (years) }\end{array}$ & Male & Female & Total \\
\hline $0-9$ & $32(29.6)$ & $\mathrm{N}(\%)$ & $\mathrm{N}(\%)$ \\
$10-19$ & $69(63.9)$ & $70(49.6)$ & $139(55.8)$ \\
$20-29$ & $3(2.8)$ & $30(21.3)$ & $33(13 \cdot 3)$ \\
$30-39$ & $3(2.8)$ & $10(7.1)$ & $13(5.2)$ \\
$40-49$ & $1(0.9)$ & $2(1.4)$ & $3(1.2)$ \\
Total & $108(100.0)$ & $141(100.0)$ & $249(100.0)$ \\
\hline
\end{tabular}

Table 2: Prevalence of dental anomalies

\begin{tabular}{ll}
\hline Dental anomalies & $\begin{array}{l}\text { Frequency } \\
(\%)\end{array}$ \\
\hline Taurodontism & $43(61.4)$ \\
Congenitally missing teeth & $8(11.4)$ \\
Supernumerary & $5(7.1)$ \\
Odontoma & $4(5.7)$ \\
Transposition & $2(2.9)$ \\
Peg shaped lateral & $2(2.9)$ \\
$\begin{array}{l}\text { Peg shaped lateral and } \\
\text { congenitally \& missing teeth } \\
\text { Supernumerary and taurodontism }\end{array}$ & $1(1.4)$ \\
$\begin{array}{l}\text { Congenitally missing teeth \& } \\
\text { supernumerary }\end{array}$ & $1(1.4)$ \\
Dilaceration & $1(1.4)$ \\
\hline & $70(100.0)$ \\
\hline
\end{tabular}


Radiographic findings among orthodontic patients

Table 3: Arch distribution of individual dental anomalies

\begin{tabular}{|c|c|c|c|c|}
\hline Dental anomalies & Arch distribution & & & \\
\hline & Maxilla N (\%) & $\begin{array}{l}\text { Mandible N } \\
(\%)\end{array}$ & $\begin{array}{l}\text { Both arches } \mathrm{N} \\
(\%)\end{array}$ & $\begin{array}{l}\text { Total N } \\
(\%)\end{array}$ \\
\hline Taurodontism & $24(55.8)$ & $3(50.0)$ & $16(76.2)$ & $43(61.4)$ \\
\hline Congenitally missing teeth & $5(11.6)$ & $1(16.7)$ & $2(9.5)$ & $8(11.4)$ \\
\hline Supernumerary & $5(11.6)$ & $0(0.0)$ & $0(0.0)$ & $5(7.1)$ \\
\hline Odontoma & $4(9 \cdot 3)$ & $0(0.0)$ & $0(0.0)$ & $4(5 \cdot 7)$ \\
\hline Transposition & $1(2.3)$ & $1(16.7)$ & $0(0.0)$ & $2(2.9)$ \\
\hline Peg shaped lateral & $2(4.6)$ & $0(0.0)$ & $0(0.0)$ & $2(2.9)$ \\
\hline $\begin{array}{l}\text { Peg shaped lateral and congenitally } \\
\text { missing teeth }\end{array}$ & $2(4.6)$ & $0(0.0)$ & $0(0.0)$ & $2(2.9)$ \\
\hline Supernumerary and taurodontism & $0(0.0)$ & $0(0.0)$ & $1(4.8)$ & $1(1.4)$ \\
\hline $\begin{array}{l}\text { Congenitally missing teeth and } \\
\text { supernumerary }\end{array}$ & $0(0.0)$ & $0(0.0)$ & $1(4.8)$ & $1(1.4)$ \\
\hline Dilaceration & $0(0.0)$ & $1(16.7)$ & $0(0.0)$ & $1(1.4)$ \\
\hline Bifid root & $0(0.0)$ & $0(0.0)$ & $1(4.8)$ & $1(1.4)$ \\
\hline Total & $43(100.0)$ & $6(100.0)$ & $21(100.0)$ & $70(100.0)$ \\
\hline
\end{tabular}

Table 4: Cross tabulation of the dental anomalies with age and gender of patients

\begin{tabular}{|c|c|c|c|c|c|c|c|c|c|c|c|}
\hline \multicolumn{3}{|c|}{ Dental anomalies } & \multicolumn{4}{|c|}{ age(years) } & \multirow{2}{*}{\multicolumn{2}{|c|}{$30-39$}} & \multirow{2}{*}{\multicolumn{2}{|c|}{$40-49$}} & \multirow{3}{*}{$\begin{array}{l}\text { Total } \\
\text { N (\%) }\end{array}$} \\
\hline & $0-9$ & & $10-19$ & & $20-29$ & & & & & & \\
\hline & M & $\mathrm{F}$ & M & $\mathrm{F}$ & M & $\mathrm{F}$ & $\mathrm{M}$ & $\mathrm{F}$ & M & $\mathrm{F}$ & \\
\hline & $\mathrm{N}(\%)$ & $\mathrm{N}(\%)$ & $N(\%)$ & $\mathrm{N}(\%)$ & $\mathrm{N}(\%)$ & $\mathrm{N}(\%)$ & $\mathrm{N}(\%)$ & $\mathrm{N}(\%)$ & $N(\%)$ & $N(\%)$ & \\
\hline Cong Miss & $0(0.0)$ & $\mathrm{o}(0.0)$ & $2(9.1)$ & $2(7 \cdot 7)$ & $\mathrm{o}(0.0)$ & $3(37.5)$ & $0(0.0)$ & $1(100.0)$ & $0(0.0)$ & $0(0.0)$ & $8(11.4)$ \\
\hline Supernum & $0(0.0)$ & $2(33.3)$ & $0(0.0)$ & $2(7 \cdot 7)$ & $0(0.0)$ & $1(12.5)$ & $0(0.0)$ & $0(0.0)$ & $0(0.0)$ & $0(0.0)$ & $5(7.1)$ \\
\hline Peg Lat & $0(0.0)$ & $0(0.0)$ & $2(9.1)$ & $0(0.0)$ & $0(0.0)$ & $0(0.0)$ & $0(0.0)$ & $0(0.0)$ & $0(0.0)$ & $0(0.0)$ & $2(2.9)$ \\
\hline $\begin{array}{l}\text { Peg Lat \& } \\
\text { Cong Miss }\end{array}$ & $0(0.0)$ & $0(0.0)$ & $0(0.0)$ & $2(7.7)$ & $0(0.0)$ & $0(0.0)$ & $0(0.0)$ & $0(0.0)$ & $0(0.0)$ & $0(0.0)$ & $2(2.9)$ \\
\hline $\begin{array}{l}\text { Supernum \& } \\
\text { Taurodont }\end{array}$ & $0(0.0)$ & $0(0.0)$ & $1(4 \cdot 5)$ & $0(0.0)$ & $0(0.0)$ & $0(0.0)$ & $0(0.0)$ & $0(0.0)$ & $0(0.0)$ & $0(0.0)$ & $1(1.4)$ \\
\hline Bifid Root & $0(0.0)$ & $0(0.0)$ & $0(0.0)$ & $1(3.8)$ & $0(0.0)$ & $0(0.0)$ & $0(0.0)$ & $0(.0 .0)$ & $0(0.0)$ & $\mathrm{o}(0.0)$ & $1(1.4)$ \\
\hline Total & $5(100.0)$ & $6(100.0)$ & $22(100.0$ & $26(100.0$ & $2(100.0$ & 8(100.0 & $0(0.0)$ & 1 (100.0 & $0(0.0)$ & $0(0.0)$ & $70(100.0$ \\
\hline
\end{tabular}

Taurodont $=$ Taurodontism, Cong Miss= Congenitally missing teeth, Supernum= Supernumerary, Transpos $=$ Transposition, Peg Lat= Peg shaped lateral, Dilacera= Dilaceration, 
Table 5: Cross tabulation of congenitally missing teeth with the age and gender of patients

\begin{tabular}{|c|c|c|c|c|c|c|c|c|c|c|c|}
\hline \multicolumn{5}{|c|}{ Congenitally missing } & \multicolumn{7}{|c|}{ teeth (years) } \\
\hline & $0-9$ & & $10-19$ & & $20-29$ & & 30-39 & & $40-49$ & & Total \\
\hline & $M$ & $\mathrm{~F}$ & $\mathrm{M}$ & $\mathrm{F}$ & $\mathrm{M}$ & $\mathrm{F}$ & $\mathrm{M}$ & $\mathrm{F}$ & $\mathrm{M}$ & $\mathrm{F}$ & $\mathrm{N}$ \\
\hline & $\mathrm{N}(\%)$ & $\mathrm{N}(\%)$ & $\mathrm{N}(\%)$ & $\mathrm{N}(\%)$ & $\mathrm{N}(\%)$ & $\mathrm{N}(\%)$ & $\mathrm{N}(\%)$ & $\mathrm{N}(\%)$ & $\mathrm{N}(\%)$ & $\mathrm{N}(\%)$ & $(\%)$ \\
\hline Lateral & $0(0.0)$ & $0(0.0)$ & $0(0.0)$ & $1(25.0)$ & $1(100.0)$ & $2(50.0)$ & $0(0.0)$ & $1(100.0)$ & $0(0.0)$ & $0(0.0)$ & $5(45 \cdot 5)$ \\
\hline Canine & $0(0.0)$ & $0(0.0)$ & $0(0.0)$ & $0(0.0)$ & $\mathrm{o}(0.0)$ & $1(25.0)$ & $0(0.0)$ & $\mathrm{O}(0.0)$ & $0(0.0)$ & $0(0.0)$ & $1(9.1)$ \\
\hline Cen \& Lat & $0(0.0)$ & $0(0.0)$ & $0(0.0)$ & $1(25.0)$ & $0(0.0)$ & $0(0.0)$ & $0(0.0)$ & $0(0.0)$ & $0(0.0)$ & $0(0.0)$ & $1(9.1)$ \\
\hline $\begin{array}{l}\text { Cen, Lat, } \\
\text { Can \& 2PM }\end{array}$ & $0(0.0)$ & $0(0.0)$ & $1(100.0)$ & $0(0.0)$ & $0(0.0)$ & $0(0.0)$ & $0(0.0)$ & $0(0.0)$ & $0(0.0)$ & $0(0.0)$ & $1(9.1)$ \\
\hline Lat \& 2PM & o o.o) & $0(0.0)$ & $0(0.0)$ & $1(25.0)$ & $0(0.0)$ & $0(0.0)$ & $0(0.0)$ & $0(0.0)$ & $0(0.0)$ & $0(0.0)$ & $1(9.1)$ \\
\hline Total & $0(0.0)$ & $0(0.0)$ & $1(100.0)$ & $4(100.0)$ & $1(100.0)$ & $4(100.0)$ & $0(0.0)$ & $1(100.0)$ & $0(0.0)$ & $0(0.0)$ & $11(100.0)$ \\
\hline
\end{tabular}

Lat= Lateral incisor, Can= Canine, Cen= central incisor, $2 \mathrm{PM}=$ second premolar, $\&=$ and

\section{Dental anomalies}

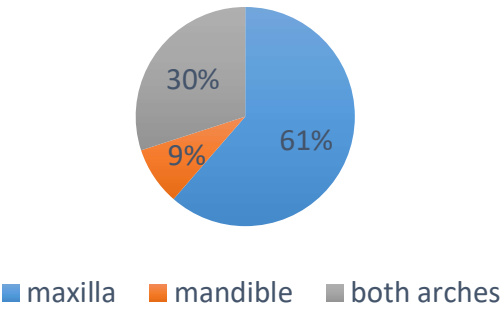

Fig 1: Prevalence of dental anomalies in the dental arches

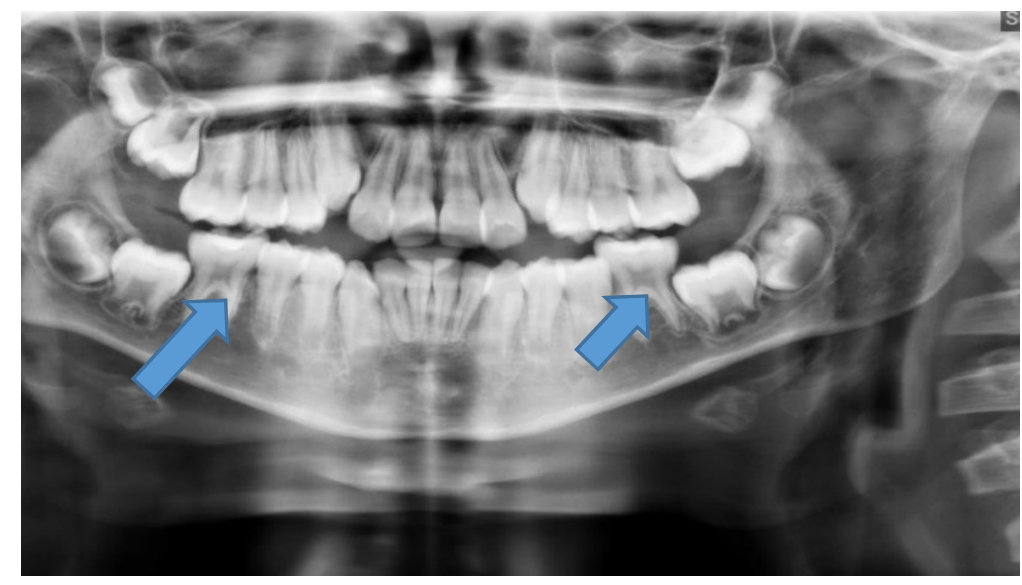

Fig 2: Taurodontism of the mandibular first permanent molars 


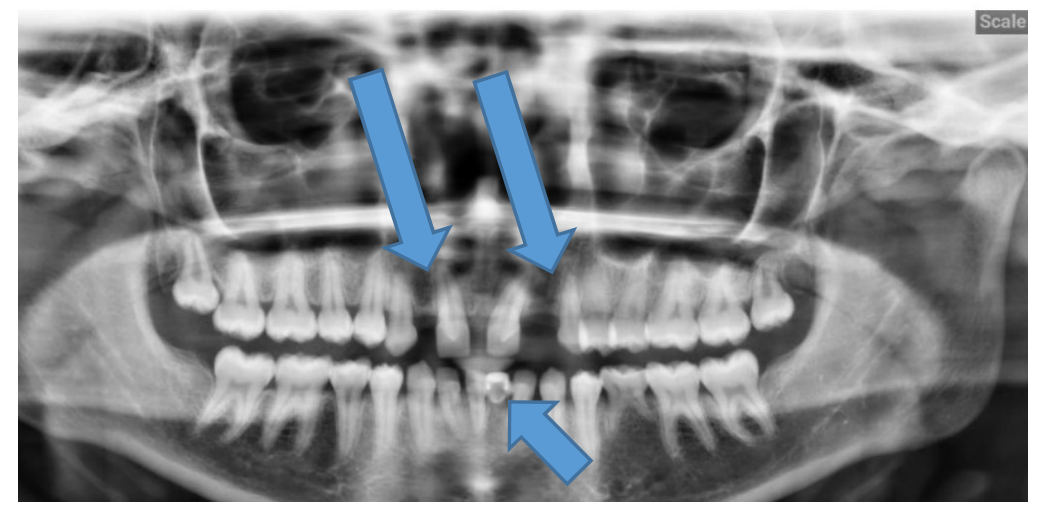

Fig 3: Mandibular mesiodens and congenitally missing maxillary lateral incisors

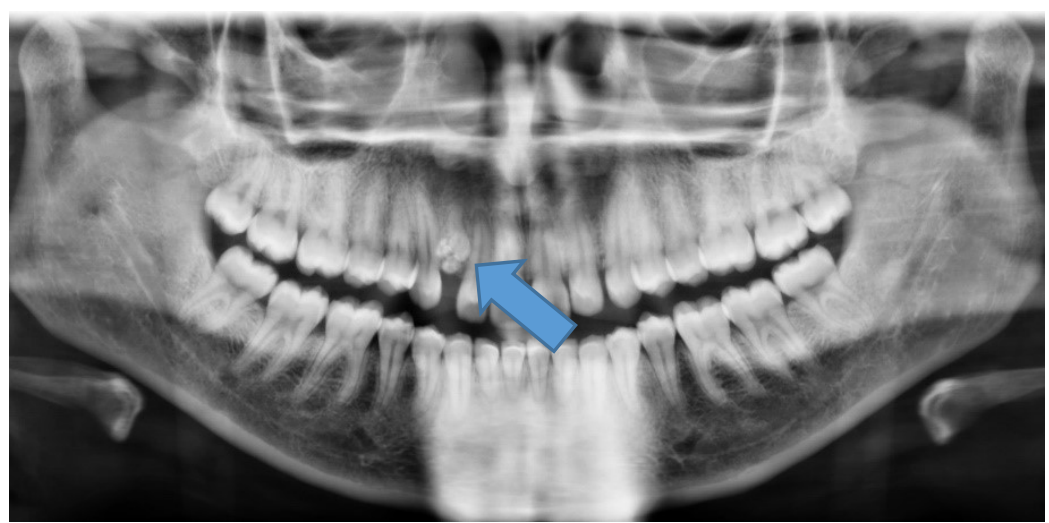

\section{Discussion}

Fig 4: Odontoma

Dental anomalies may be chance findings among orthodontic patients. ${ }^{2}$ During routine radiologic investigations of our patients with an orthopantomogram, about a quarter of them were found to have at least one dental anomaly. These anomalies were more commonly seen in the maxillae and in female patients and included taurodontism, missing teeth, supernumeraries, odontomas, peg shaped lateral incisors, transpositions and bifid roots. The commonest was taurodontism whilst bifid root and dilaceration were the least common anomalies seen radiographically.

The prevalence of all the dental anomalies seen in our study was $28.1 \%$ which is comparable to studies carried out in Nigeria and India. ${ }^{9,13}$ but much lower than prevalence seen in a Brazilian population $(56.9 \%) .{ }^{5}$ These variations could be due to racial differences, sample size, study design and also diagnostic criteria. ${ }^{2,3}$ In studies carried out among Saudi Arabians, Iranians, Caucasians and South Western Nigerians, these anomalies were seen more in the maxilla and females which is similar to our findings. $37,7,9,10,12$ However, a study have reported dental anomalies to be more common in males ${ }^{14}$ while another did not find any gender predilection. ${ }^{13}$ These differences may be due to genetics, racial variation and nature of subjects examined. $3{ }^{311,12}$ Taurodontism is defined by Wiktop as "a tooth with a large pulp chamber with bifurcation or trifurcation displaced apically such that the chamber has larger apical-occlusal height than in normal teeth and with absence of constriction at the cemento-enamel junction and the distance from the bifurcation or trifurcation is greater than the occlusal-cervical distance ${ }^{\prime \prime} .{ }^{6}$ It is also known as bull tooth and was the most common anomaly amongst our patients which is consistent with a study among Iranians. ${ }^{7}$ However, studies carried out among Caucasians and Saudi Arabians indicate that taurodontism is the least common dental anomaly. ${ }^{10,11}$ This may be due to under reporting as diagnosis is subjective. ${ }^{10}$. Both genders had equal distribution in our study which is 
consistent with a study which showed no sex predilection for taurodontism. ${ }^{10}$

Taurodontism is a vital radiological finding which is noteworthy during orthodontic treatment in that the anchorage value of the affected tooth is reduced due to reduction in the root surface area. The use of headgear is contraindicated in molars with taurodontism due to limited root support. ${ }^{15}$ Also, taurodontism is associated with increased tendency to root resorption during orthodontic treatment, orthodontists are therefore advised to avoid orthodontic movement of taurodont teeth. ${ }^{15}$

Congenitally missing teeth is one of the commonest dental anomalies worldwide with a prevalence rate ranging from 1.6 to $45.7 \%{ }^{16}$ The prevalence rate in our study was $4.4 \%$ with a higher prevalence in females which is comparable to other studies carried out among Saudi Arabians ${ }^{3,10,11}$ Iraqis ${ }^{17}$ and Indians. ${ }^{13}$ The most common congenitally missing teeth in our study were the maxillary lateral incisors. This is consistent with other studies among Caucasians ${ }^{12,}$ Saudi Arabians ${ }^{10,11}$ Iraqis $^{17}$ and Sudanese ${ }^{8}$ but in contrast to study on Saudi Arabians in the Eastern Province which reported mandibular second premolars as the most common congenitally missing teeth. ${ }^{3}$

Supernumerary teeth have been reported in the literature to be more common in males than in females. ${ }^{18-22}$ or to be of equal distribution among genders. ${ }^{3}$ However, we found a higher prevalence among our female patients which has also been reported in Sweden. ${ }^{23}$ This variation could be due to race or ethnicity, dentition type, position in the arch, diagnostic tool and assessment methods used in the different studies. ${ }^{24}$ Odontomas also known as odontomes are dental hamartomas. ${ }^{25}$ These were not commonly seen in our study which is similar to findings in another study in Columbia. ${ }^{2}$

Transposition is a positional interchange of two adjacent (usually) permanent teeth located within the same quadrant of a dental arch reported to be more common in the maxilla than mandible. ${ }^{10,11}$ However, we found no arch predilection in our study. It has been reported to affect both gender equally ${ }^{10,11}$ however, in our study it was only seen in females. This is consistent with a study which reported higher prevalence among females. ${ }^{3} \mathrm{t}$ is one of the four least common dental anomalies among our patients which is similar to a study carried out in South Western
Nigeria ${ }^{22}$ but dissimilar to studies on Saudi Arabians and Caucasians which reported transposition as the most common dental anomaly. ${ }^{10,11}$

Peg shaped lateral incisors were seen in $1.6 \%$ of the studied population. This is similar to studies carried out in South West Nigeria $(1.4 \%)^{21}$ and Saudi Arabia. ${ }^{3}$ There was no gender predilection in our study however when seen in females, it was associated with a missing contralateral tooth. This is similar to a study amongst Saudi Arabians ${ }^{10,11}$ but contrasts with other studies which showed female preponderance. ${ }^{26}$

Dilaceration was not very common in our study with a prevalence of $0.4 \%$. This finding is consistent with studies which reported it as one of the least common dental anomalies ${ }^{8}$ but contrasts with other studies which showed it to be quite common. $3,5,7$

Bifid root is also one of the two least common dental anomalies in the present study with a prevalence of $0.4 \%$ of the total population. This is similar to a study by AlHumaid et $\mathrm{al}^{3}$ on Saudi and non-Saudi patients with a prevalence of $0.6 \%$ of their total population.

\section{Conclusion}

About a quarter of our patients had at least one dental anomaly. The most common dental anomaly was taurodontism, the least common were dilaceration and bifid root. Anomalies were more frequent in the females and in the maxilla.

Dental anomalies are relatively common among orthodontic patients but may be incidental findings. Thus, we advocate that all radiographs should be carefully assessed by the orthodontist in order to assist in treatment planning and improve the comprehensive management of these patients.

\section{References}

1. Panoramic radiographic assessment in Orthodontics. In: Panoramic Radiographic. Springer, Berlin, Heidelberg 2007. pp83-89.

2. Hernandez G, Plaza SP, Cifuentes D, Villalobos LM, Ruiz LM. Incidental findings in preorthodontic treatment radiographs. Int Dent J 2018; 68:320-326.

3. ALHumaid J, Buholayka $M$, Thapsum $A$, Alhareky $M$, Abdelsalam $M$, Bughsan $A$. Investigating prevalence of dental anomalies in Eastern Province of Saudi Arabia through digital orthopantomogram. Saudi J Biol Sci 2021; 28:2900-2906. 
4. Almaz ME, Sönmez IS, Oba AA. Prevalence and Distribution of Developmental Dental Anomalies in Pediatric Patients. Meandros Med Dent J 2017; 18:130-133.

5. Goncalves-Filho AJ, Moda, LB, Oliveira RP, Ribeiro $A L$, Pinheiro JJ, Alver-Junior SR. Prevalence of dental anomalies on panoramic radiographs in a population of the state of Pará, Brazil. Indian J. Dent. Res. 2014; 25 (5), 648-652.

6. Jahanimoghadam F. Dental Anomalies: An Update. Adv Hum Biol 2016; 6:112-118.

7. Saberi, E.A., Ebrahimipour, S. Evaluation of developmental dental anomalies in digital panoramic radiographs in Southeast Iranian Population. J Int Soc Prev Community Dent 2016; 6 (4), 291-295.

8. Hassan DA, Abuaffan AH, Hashim HA. Prevalence of hypodontia in a sample of Sudanese orthodontic patients. J Orthod Sci. 2014;3(3):63-67.

9. Temilola DO, Folayan MO, Fatusi O, Chukwumah NM, Onyejaka N, Oziegne E, Oyedele T, Kolawole KA, Agbaje $H$. The prevalence, pattern and clinical presentation of developmental dental hard-tissue anomalies in children with primary and mix dentition from lleIfe, Nigeria. BMC Oral Health 2014; 14:125.

10. Alassiry AM. Prevalence and distribution of selected dental anomalies in Najran City of Saudi Arabia. Egypt Dent J 2020; 66:1471-1481.

11. Lagana G, Venza N, Borzabadi-Farahani A, Fabi F, Danesi C, Cozza P. Dental anomalies: Prevalence and associations between them in a large sample of non-orthodontic subjects, a cross-sectional study. BMC Oral Health 2017; 11:17(1):62-6g.

12. Sella Tunis T.; Sarne O, Hershkovitz I, Finkelstein T, Pavlidi AM, Shapira Y, Davidovitch M., Shpack N. Dental Anomalies' Characteristics. Diagnostics 2021; 11: 1161.

13. Kathariya MD, Nikam AP, Chopra K, Patil NN, Raheja H., Kathariya R. Prevalence of dental anomalies among school going children in India. $J$ Int Oral Health 2013; 5(5):10-14.

14. Alswayyed T, Al Qutub M, Al Matrodi A, AlKanani N, Al Jhany N, Makhdoum L. Patterns of dental anomalies in patients attending for orthodontic treatment in King Abdul-Aziz
Medical City, Riyadh Saudi Arabia. Int J Dent Oral Health 2018; 4(2):8-13.

15. Datana S, Agarwal SS, Bhandari SK, Jain D. Implication of taurodontism in orthodontic diagnosis and treatment planning: A review and case report. J Dent Def Sect 2021; 15:43-46.

16. Neville BW, Damm DD, Allen CM, Chi AC. Oral and Maxillofacial Pathology 4th ed. Elsivier Health Sciences 2015.

17. Jasim $\mathrm{HH}$. Prevalence of congenitally missing teeth (radiographic study). Annals Dent Spec 2020; 8(1):10-19.

18. Subasioglu A, Savas S, Kucukyilmaz E, Kesim S, Yagci A, Dundar M. Genetic background of supernumerary teeth. Eur J Dent 2015; 9(1):153158.

19. Chou S-T, Chang H-P, Yang Y-H, Lung C-Y, Tseng Y-C, Pan C-Y, Cheng J-H. Characteristics of supernumerary teeth among nonsyndromic dental patients. J Dent Sci 2015; 10:133-138.

20. Parolia A, Kundabala M, Dahal M, Mohan M, Thomas MS. Management of supernumerary teeth. J Conserv Dent 2011; 14(3):221-224.

21. Fleming PS, Xavier GM, DiBiase AT, Cobourne MT. Revisiting the supernumerary: the epidemiological and molecular basis of extra teeth. Br Dent J 2010; 208:25-30.

22. Onyeaso $\mathrm{CO}$, Onyeaso AO. Occlusal/dental anomalies found in a random sample Of Nigerian School Children. Oral Health Prev Dent 2006; 4(3):181-186.

23. Blackman B, Wahlin YB. Variations in number and morphology of permanent teeth in 7-year Swedish Children. Int J Paedtr Dent 2001; 11(1):11-17.

24. Mallineni SK. Supernumerary teeth: Review of the literature with recent updates. Conference papers in Science 2014; Article ID 764050 6 pages.

25. El-Naggar AK, Chan JKC, Grandis JR, Takata T, Slootweg P. WHO Classification of head and neck tumours. 4th ed. Vol 9 Lyon, France: International Agency Research on Cancer (IARC) 2017.

26. Hua $F$, He H, Ngan P, Bouzid W. Prevalence of peg-shaped maxillary permanent lateral incisors: A meta-analysis. Am J Orthod Dentofacial Orthop. 2013; 144(1):97-10 